\section{Reproductive management of the goat}

Citation: González-Maldonado, J., Martínez-Moreno, E. A., DomínguezCaballero, J. F, Herrera-Corredor, C. A., \& Gallegos-Sánchez, J. (2021). Reproductive management of the goat. Agro Productividad. https://doi.org/ 10.32854/agrop.v14i8.2059

Editor in Chief: Dr. Jorge Cadena Iñiguez

Received: February 17, 2021.

Accepted: August 21, 2021.

Published on-line: October 14, 202

This work is licensed under a Creative Commons Attribution-NonCommercial 4.0 International license.

\section{González-Maldonado, Juan ${ }^{1,2}$; Martínez-Moreno, Erika A. ${ }^{3}$; Domínguez-Caballero, Javier F. ${ }^{3}$; Herrera-Corredor, Camelia A. ${ }^{4}$; Gallegos-Sánchez, Jaime ${ }^{\text {1* }}$}

${ }^{1}$ Colegio de Postgraduados, Campus Montecillo, Ganadería, km 36.5, carretera federal México-Texcoco, Montecillo, Edo. de México, México. C.P. 56230.

2 Instituto de Ciencias Agrícolas. Universidad Autónoma de Baja California. Carretera a Delta S/N Ejido Nuevo León. Mexicali, Baja California, México. C.P. 21705.

3 Universidad Autónoma Chapingo, Departamento de Zootecnia, Texcoco, Edo. de México, México. Carretera federal México-Texcoco, Texcoco, Edo de México, México. C.P. 56230.

4 Facultad de Agronomía. Universidad Autónoma de San Luís Potosí. Soledad de Graciano Sánchez, San Luis Potosí, México. A. P. 22.

* Correspondence: gallegos@colpos.mx

\begin{abstract}
Objective: To share technical aspects with specialists in animal reproduction and producers that could help to improve the reproductive capacity of caprine livestock.

Design/Methodology/Approach: Scientific evidence and experience in the reproductive management of goats are the basis that sustains the information presented in this article.

Results: The goat is widely distributed in Mexico; it is a species with seasonal reproductive activity, but of easy manipulation with hormonal and natural means. Presently there is a large variety of biotechnologies that can be applied in the production units, to potentiate the reproductive activity of the goat.

Study Limitations/Implications: The lack of knowledge and the lack of consulting and technical training limit the productive and reproductive potential of goat breeding in Mexico.

Findings/Conclusions: Knowledge of the reproductive physiology of the goat and understanding of the means available to manipulate it guarantees its reproduction at the time and in the conditions desired by the producer and the market.
\end{abstract}

Keywords: biotechnology; reproductive strategy; fertility; gestation.

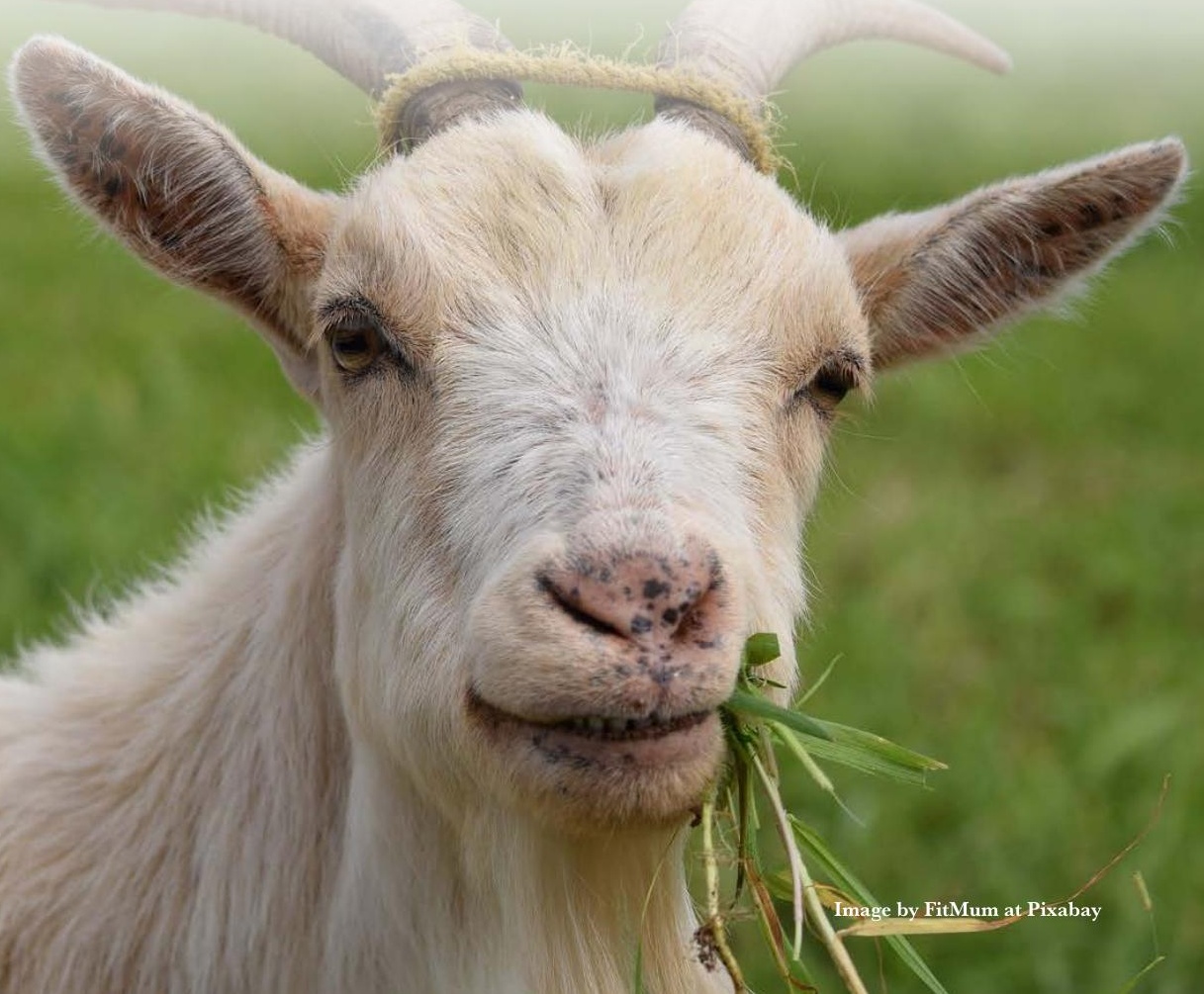




\section{INTRODUCTION}

The goat is a seasonal polyestrous species; that is, it presents many estruses, at specific intervals of time but only during one season of the year, when the days are shorter than the nights (reproductive season). During these days, the male is also sexually active and the intensity of its smell is increased, stimulating the reproductive activity of the doe. During seasonal anestrus (season of the year when the days are longer than the night), even when there is follicular development in the females' ovaries, external signs of estrus, ovulations or formation of corpora lutea are not observed. In general, in Mexico the reproductive season of goats happens from September to February, and in the males from May to December. In particular, in the central part of the country it has been observed that mounting begins at the end of May. The differences in the beginning and length of the reproductive season is an effect of the latitude: as it approaches the equator, the effect of the photoperiod is lower and other factors such as the rainy season and the availability of food are of greater importance in the establishment of the reproductive season. The objective of this study is to present technical aspects that help to improve the reproductive ability of caprine livestock.

\section{Estrus cycle}

The estrus cycle (time interval between one estrus and the next) of the doe has an average duration of 21 days (Fatet et al., 2011) but it can vary from 16 to 28 (Chemineau, 1983). The duration of the estrus (period in which the doe accepts mounting) varies from 14 to $48 \mathrm{~h}$ (Fatet et al., 2011). The time at which the pre-ovulatory peak of the luteinizing hormone $(\mathrm{LH})$ and the ovulation take place varies between 8-13 and 28-37 h, with regard to the beginning of the estrus (Menchaca et al., 2007). After ovulation, the teak and granulose cells will originate the one or many corpora lutea (CL), in charge of producing progesterone $\left(\mathrm{P}_{4}\right)$. In the case of does that have not been inseminated or when the maternal recognition of gestation does not happen, a regression process of the CL will begin, induced by prostaglandin $\mathrm{F}_{2 \alpha}\left(\mathrm{PGF}_{2 \alpha}\right)$, between days 16-18 of the estrus cycle and there will be a new estrus (Figure 1; Fatet et al., 2011; Balaro et al., 2017). On the contrary, if the doe is pregnant, the CL will remain during the gestation period (148-154 days).

\section{Estrus synchronization}

Once females have reached puberty, they can be inseminated in the next estrus. If the producer requires for the females to be inseminated in a short period of time or outside the reproductive season, then synchronization or induction of the estrus can be done. This allows the homogeneous presentation of the estruses in a specific moment. One of the main advantages of the synchronization and induction of estrus is that it allows programming births, obtaining the kid harvest and the milk production when the price and the market conditions are the most favorable for the producer. The synchronization of estruses is achieved through the exogenous application of some of the hormones that control the estrus cycle of the doe. They are $\mathrm{GnRH}, \mathrm{P}_{4}$, and $\mathrm{PGF}_{2 \alpha}$. The first induces the liberation of the follicle-stimulating hormone (FSH) and LH. The FSH stimulates follicular growth and the LH unchains the events that cause the ovulation of pre-ovulatory follicle or follicles (Figure 1). 


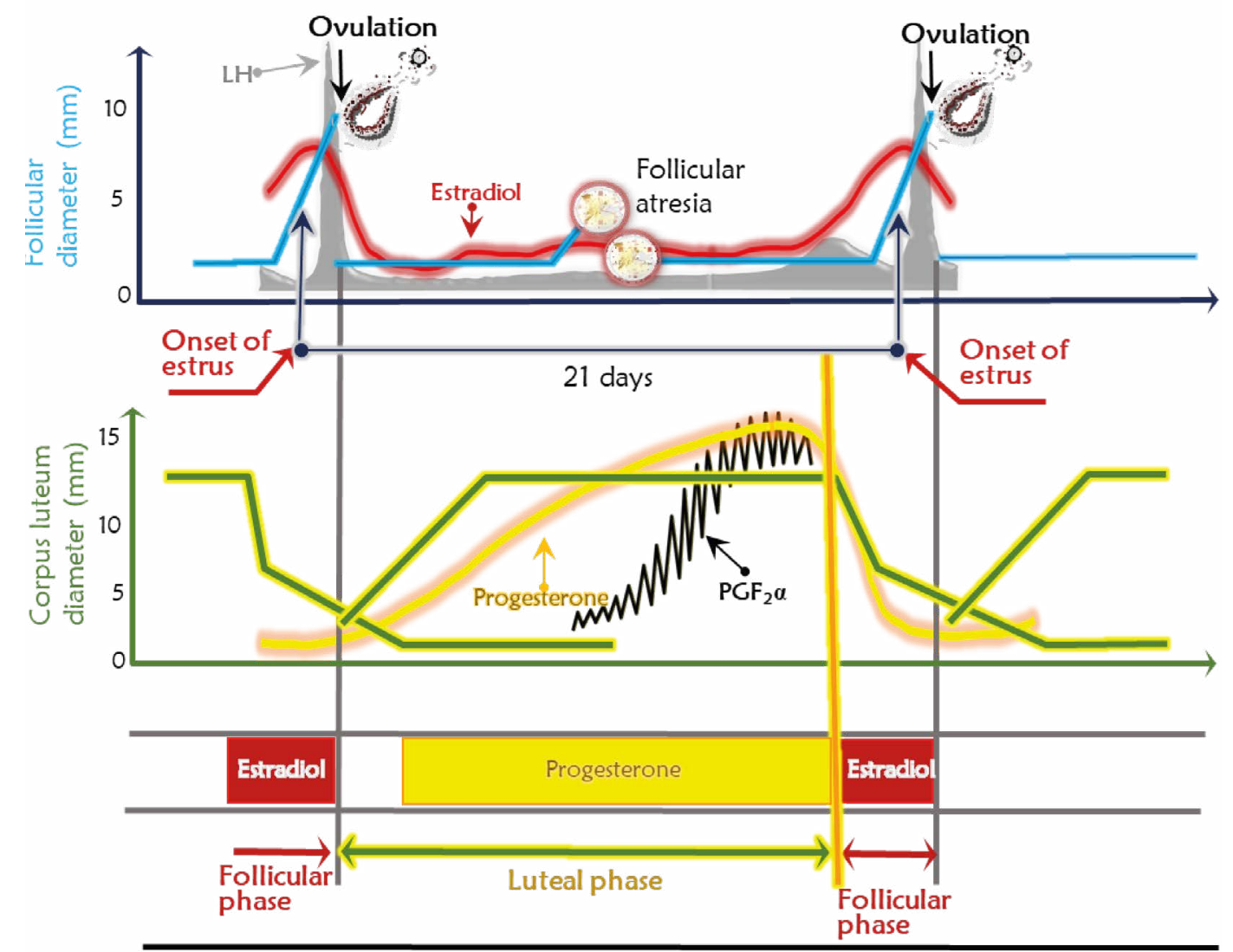

$-1-2-3-401234456789101112131415161718192021$ days estrous cycle

Figure 1. Picture depicting the estrous cycle in goats. The red, yellow, green, blue and black lines indicate the variations in blood estradiol and progesterone concentrations, the diameter of the corpus luteum and follicle, and the prostaglandin $\left(\mathrm{PGF}_{2 \alpha}\right)$ secretion pattern throughout the estrous cycle, respectively. The grey chart depicts the LH pattern secretion.

The synchronization protocols can be divided into two: those that use exogenous progesterone and those that do not use it. However, when $\mathrm{P}_{4}$ is not used, the other hormones must be applied during the luteum phase. $\mathrm{P}_{4}$ is applied for periods that generally vary from five to 14 days, since it is known that $\mathrm{P}_{4}$ participates in the presentation of estrus so its presence in the organism, whether supplemented or natural, is mandatory. In the Mexican market there are two mediums to supplement it, by sponges or by controlled release devices (CIDR; Figure 2). Both are applied intra-vaginally. Apart from the material that they are made of, the main difference between both is that the sponges contain progesterone analogues (fluorogestone acetate or medroxyprogesterone), while the CIDR contain the natural source of this hormone. In addition, the CIDR can be reused while the sponges are used only once.

$\mathrm{PGF}_{2 \alpha}$ is generally applied $48 \mathrm{~h}$ before or at the moment of withdrawing the sponge or the CIDR, or at the time of applying the equine chorionic gonadotropin (eCG). The regression of $\mathrm{CL}$ by the action of $\mathrm{PGF}_{2 \alpha}$, in combination with the withdrawal of the sponge or CIDR, causes a sudden decrease of the concentrations of $\mathrm{P}_{4}$, provoking the appearance of the external signs of estrus, as a result of the increase of $\mathrm{E}_{2}$ produced by the one or 

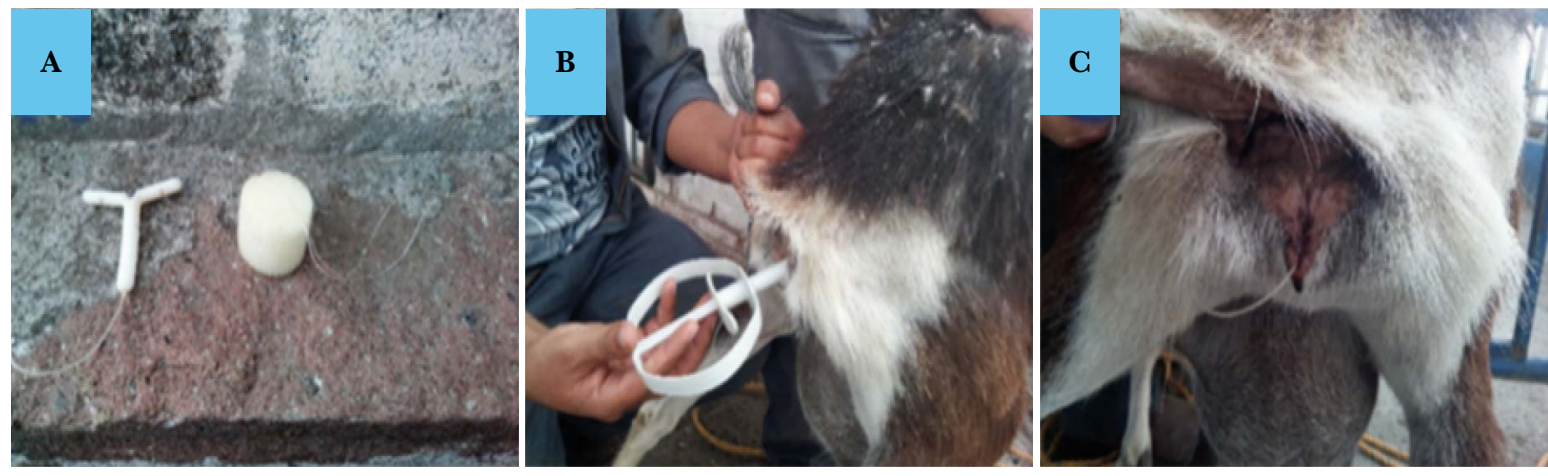

Figure 2. (A) Picture depicting a CIDR and sponge used in goats to estrus synchronization. (B) The CIDR and sponge are intravaginally inserted into the animal. These vaginal inserts have a tail that normally remains exteriorized after their application. (C) The removal of the CIDR and sponge is carried out by pulling out their protruding tail; if a goat shows not protruding tail of the vaginal inserts, a vaginal examination by speculum is recommended to ensure that they are not located deep into the vagina.

many pre-ovulatory follicles. The eCG has a similar action to the FSH; the objectives of its application, according to the injected dose, are to increase the number of pre-ovulatory follicles and the homogenization of the appearance of estruses. The estrus in does takes place between 26 and $47 \mathrm{~h}$ after the withdrawal of the sponge or CIDR (Navanukraw et al., 2014) and it shortens even more the time with the application of the eCG.

The protocols that do not use exogenous $\mathrm{P}_{4}$ are based mainly on the intramuscular application of $\mathrm{PGF}_{2 \alpha}$, alone or in combination with the GnRH. The main disadvantage of these protocols is that they can only be used during the reproductive season (short days) and in presence of a CL. This happens because it depends on the natural contribution of $\mathrm{P}_{4}$ by the CL and since this ovarian structure does not exist, the exogenous supplementation of $\mathrm{P}_{4}$ during anestrus is essential for the implementation of any induction protocol. The effectiveness of the induction of estruses, through the use of $\mathrm{PGF}_{2 \alpha}$, depends on the presence of a CL at the time of its application.

\section{Synchronization scheme}

The detection of estruses is done with the help of a buck with askew penis, vasectomized, or a "whole" one with apron (Figure 3), to avoid early or unwanted mating. The bucks are introduced to the pen of the does treated at intervals of $6 \mathrm{~h}$, after having ended the hormonal treatment. The does that accept mounting are considered to be in estrus. It is advisable to record the time at which estrus was detected, to program the insemination (natural mounting, NM; artificial insemination, AI). In the case that it is not possible or when detecting the estrus is not meant to be done, there is the option of the use of induction or synchronization protocols with insemination at a fixed time. The insemination can be performed between 43 and $54 \mathrm{~h}$ after withdrawing the sponge or CIDR (Holtz et al., 2008; Vilariño et al., 2011; Sen and Onder, 2016). An insemination protocol at a set time is ovsynch, which is adopted from bovines. It consists in the injection of GnRH on day zero, followed by another of $\mathrm{PGF}_{2 \alpha}$ and $\mathrm{GnRH}$ seven and nine days later. The insemination is performed $16 \mathrm{~h}$ after the second injection of GnRH (Holtz et al., 2008). 


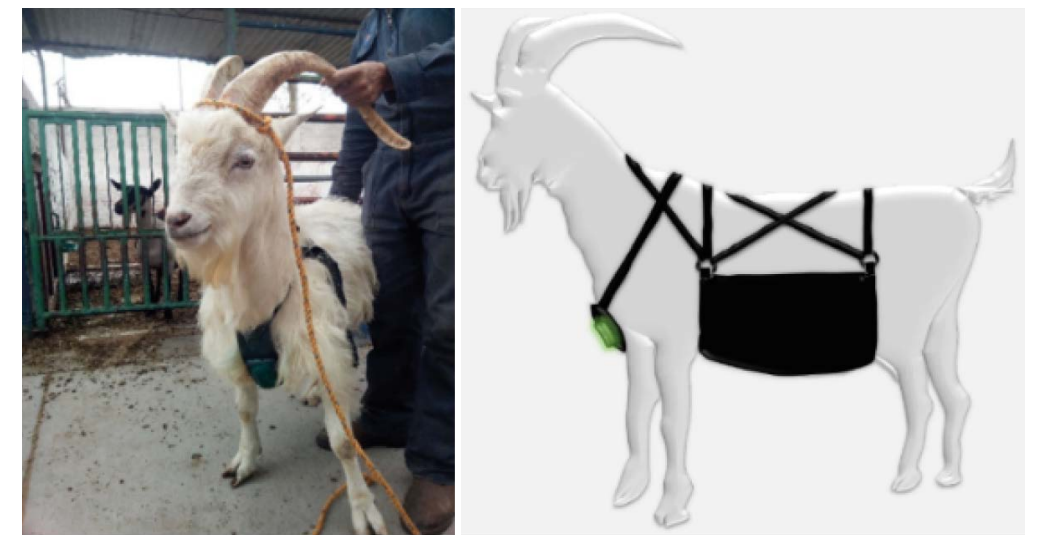

Figure 3. A Sannen buck wearing and apron and harness to avoid copulation and to identified ewes in estrus.

\section{Mating and artificial insemination (AI)}

Mating can be carried out naturally or controlled. In the first case, the buck is incorporated into a pen or a group of does at the beginning of the reproductive season. Mounting is carried out as the does enter estrus naturally. In controlled mating the buck is allowed to mount the doe 12 to $18 \mathrm{~h}$ after the estrus is detected, and mounting can be repeated at intervals of $12 \mathrm{~h}$ until the end of the estrus. This is generally done with does with synchronized estrus. In the case that there is not enough time to expose the females in estrus to the male, it can be introduced into the pen of synchronized does.

The proportion females:males to be used will depend on whether it is natural mating or with synchronized does. In the latter, the number of females per male should be lower, because the estruses will present in a short period of time. Fonseca et al. (2008) suggested that the proportion should not exceed 8:1 with synchronized estruses, with intervals between synchronizations of 3 to 4 days. This is adequate, considering that Mellado et al. (2000) reported that the males perform nine mounts per day. In natural mating, the number of females can be increased up to 75 for each male (Mellado et al., 1996). However, this will depend on the libido and experience of the buck to be used. It is advisable to place a harness (Figure 3) on the male or simply paint its chest continually, to be able to identify the females the have been mounted. Therefore, the birth date and the mating ability of the buck could be estimated. In the case that no marked does are observed, the buck should be replaced, since this indicates the inability to mount.

The goat breeder has the option of introducing new genetic material to his flock through AI; the insemination can be conducted with fresh, refrigerated or frozen semen. The first two are generally obtained from males within or close to the production unit, since their average life is limited. Contrary to these, the frozen semen can be conserved in liquid nitrogen indefinitely and transported to any part of the world. The types of insemination, available to goats, can be classified according to the site where semen is deposited in the reproductive system of the goat. These are intra-vaginal, peri-cervical, intra-cervical, and intra-uterine via trans-cervical and laparoscopy. 
The AI techniques can be carried out by the producer. However, laparoscopy implies the use of specialized equipment (laparoscope, sources of light and trocars), which can limit its routine use. In addition, it requires for animals to be deprived of food and water for a minimum period of $12 \mathrm{~h}$ before the insemination but uses a lower number of sperm cells per dose, since the semen is deposited in the uterine horns. Ritar et al. (1990) obtained between 50 and $66 \%$ pregnancies using semen doses with 5 to 60 million sperm cells through laparoscopy, while using the uterine intra- and trans-cervical insemination they obtained between 34 and $42 \%$, inseminated with doses of 80 to 160 million sperm cells. In general, the further in the reproductive system of the doe the semen is deposited, the gestation percentages will be higher. In this regard, Salvador et al. (2005) obtained $82 \%$ of pregnancies when the semen was deposited past the cervix and $37 \%$ when it was deposited into the vagina. The insemination can be carried out between 12 and $24 \mathrm{~h}$ after the estrus is detected.

\section{Male effect}

The male effect is an alternative to the conventional protocols of synchronization, which consists in the stimulation of the reproductive activity of the doe, induced by the effect (presence, smell, vocalization and mating) of the sudden introduction of the buck. The stimulation consists in the increase of the frequency of LH secretion, presentation of estrus and ovulation. According to Martínez-Alfaro et al. (2014) the pre-ovulatory peak of $\mathrm{LH}$ and the ovulation is presented at 41 and $65 \mathrm{~h}$ after the introduction of the male. However, the period between the introduction of the male and the beginning of the estrus can vary from 1.8 to 8 days (Fernández et al., 2011; Zarazaga et al., 2018). Chemineau et al. (2006) indicated that after the first ovulation induced by the male effect, if the does are not inseminated, some of them will present an estrus cycle of normal duration, while the rest will suffer a premature regression of the corpus luteum, starting a new cycle at between six and nine days after the introduction of the male.

The male effect is used during anestrus and its effectiveness in the induction of estrus depends on the male's libido. Therefore, the males should be treated in a way that they are active during seasonal anestrus. Flores et al. (2000) indicated that the males that are not stimulated prior to their incorporation with the does are incapable of inducing the reproductive activity in them. A way of stimulating the reproductive activity in the males during anestrus is through testosterone, administered at a dose of $50 \mathrm{mg}$ every third day for three weeks, which is effective in inducing the sexual behavior of the male during anestrus (Luna-Orozco et al., 2012).

The response to the male effect will depend on the physical state of the does at the time of the stimulus; the response to the male effect is lower in does with $\leq 33 \mathrm{~kg}$ of live weight and higher in does with $\geq 34 \mathrm{~kg}$ (Véliz et al., 2006). This is normal, since the heaviest does are generally dominant in the flock and will be the first to have access to the male. In addition, the proportion male:females should be taken into account. For example, it has been found that the fertility is reduced in $22 \%$ when a proportion of 1:30 is used in comparison to 1:20 (Zarazaga et al., 2018). 


\section{Reproductive biotechnologies in goats}

Reproductive biotechnologies are tools that can be used by the technician or producer to increase the reproductive potential of the flock and to promote the dissemination of outstanding animals. Some of the most used biotechnologies in goats include estrus synchronization, AI, semen extraction and freezing, super-stimulation, production, division and freezing of embryos, follicular aspiration and production of in vitro embryos. Other less common ones such as cloning, intra-cytoplasmic sperm injection, freezing of oocytes, cloning and sexing of embryos can be reviewed in Nasar et al. (2008).

Estrus synchronization and artificial insemination were reviewed in prior sections of this document. Semen extraction tends to be conducted with the help of an artificial vagina or the electro-ejaculator. The artificial vagina is the most frequently used method, since it is less stressful for the male. The volume and concentration of semen extracted varies from 0.4 to $1.27 \mathrm{~mL}$ and $1.4-3.6 \times 10^{9}$ sperm cells $\mathrm{mL}^{-1}$ (Memon et al., 1986; Karagiaannidis et al., 2000). The collected semen is mixed with cryo-preservatives and stored in liquid nitrogen, for indefinite time, for its use through AI or in the production of in vitro embryos.

Super-stimulation consists in the use of gonadotropins to induce the development of pre-ovulatory follicles, and therefore ovulations, higher than the number that would naturally occur in each estrus cycle. The gonadotropins commonly used are purified sources of FSH and eCG. The first is applied several times at an interval of $12 \mathrm{~h}$ before, during and after withdrawal of the sponge or GIDR. The eCG is applied only once, due to its longer average life. However, there is the disadvantage of provoking the persistence of pre-ovulatory follicles after the estrus, which is unfavorable for embryo development. The collection of embryos is carried out six to seven days after the estrus. The collection methods are laparotomy or via the cervix. The embryos collected can be immediately transferred to receiving does or frozen for their posterior transference. Another alternative is to divide every embryo into two halves, each of them with potential to generate a kid. It is important to mention that the receiving does of embryos must be in the same estrus cycle than the donating, at the time of the transference, to guarantee a similar hormonal medium between donor and receptor.

Follicle aspiration is carried out with the aim of collecting oocytes in situ for the production of embryos in vitro. The visualization and fixation of the ovary, to aspirate the follicles present, is carried out through laparoscopy. Once collected, the oocytes are evaluated, and those of good quality are subjected to a process of maturation, fertilization and cultivation under laboratory conditions.

\section{GONGLUSIONS}

The knowledge available about the reproductive physiology of the goat is abundant. However, it is still necessary to work on the implementation of reproductive biotechnologies within production units, so that their use becomes generalized and improvements can be made not just in reproductive parameters, but also genetics and the productivity of the flock in general. 


\section{REFERENCES}

Balaro, M.F.A., Santos, A.S., Moura, L.F.G.M., Fonseca, J.F., \& Brandão, F.Z. (2017). Luteal dynamic and functionality assessment in dairy goats by luteal blood flow, luteal biometry, and hormonal assay. Theriogenology, 95,118-126. Doi: 10.1016/j.theriogenology.2017.02.021

Chemineau, P. (1983). Effect on oestrus and ovulation of exposing creole goats to the male at three times of the year. Journal of Reproduction and Fertility, 67, 65-72. Doi: 10.1530/jrf.0.0670065

Chemineau, P., Pellicer-Rubio, M.T, Lassoued, N., Khaldi, G., \& Monniaux, D. (2006). Male-induced short oestrous and ovarian cycles in sheep and goats: a working hypothesis. Reproduction, Nutrition, Development, 46, 417-429. Doi: 10.1051/rnd:2006022

Fatet, A., Pellicer-Rubio, M.T., \& Leboeuf, B. (2011). Reproductive cycle of goats. Animal Reproduction Science, 124, 211-219. Doi: 10.1016/j.anireprosci.2010.08.029

Fernández, I.G., Luna-Orozco, J.R., Vielma, J., Duarte, G., Hernández, H., Flores, J.A., Gelez, H., \& Delgadillo, J.A. (2011). Lack of sexual experience does not reduce the responses of LH, estrus or fertility in anestrous goats exposed to sexually active males. Hormones and Behavior, 60, 484-488. Doi: 10.1016/j.yhbeh.2011.07.016

Flores, J.A., Véliz, F.G., Pérez-Villanueva, J.A., Martínez-Escalera, G., Chemineau, P., Poindron, P., Malpaux, B., \& Delgadillo, J.A. (2000). Male reproductive condition is the limiting factor of efficiency in male effect during seasonal anestrus in female goats. Biology of Reproduction, 62, 1409-1414. Doi: 10.1095/ biolreprod62.5.1409

Fonseca, J.F., Torres, G.A., Santos, A.D., Maffili, V.V., Amorim, L.S., \& Moraes, E.A. (2008). Progesterone and behavioral features when estrous is induced in Alpine goats. Animal Reproduction Science, 103, 366373. Doi: 10.1016/j.anireprosci.2007.05.013

Holtz W., Sohnrey B., Gerland M., \& Driancourt M.A. (2008). Ovsynch synchronization and fixed-time insemination in goats. Theriogenology, 69, 785-792. Doi: 10.1016/j.theriogenology.2007.10.004

Karagiannidis, A., Varsakeli, S., \& Karatzas, G. (2000). Characteristics and seasonal variations in the semen of Alpine, Saanen and Damascus goat bucks born and raised in Greece. Theriogenology, 53, 1285-1293. Doi: 10.1016/S0093-691X(00)00272-7

Luna-Orozco, J.R., Guillen-Muñoz, J.M., De Santiago-Miramontes, Mde L., García, J.E., RodríguezMartínez, R., Meza-Herrera, C.A., Mellado, M., \& Véliz, F.G. (2012). Influence of sexually inactive bucks subjected to long photoperiod or testosterone on the induction of estrus in anovulatory goats. Tropical Animal Health and Production, 44, 71-75. Doi: 10.1007/s11250-011-9889-y

Martínez-Alfaro, J.C., Hernández, H., Flores, J.A., Duarte, G., Fitz-Rodríguez, G., Fernández, I.G., Bedos, M., Chemineau, P., Keller, M., Delgadillo, J.A., \& Vielma, J. (2014). Importance of intense male sexual behavior for inducing the preovulatory LH surge and ovulation in seasonally anovulatory female goats. Theriogenology, 82, 1028-1035. Doi: 10.1016/j.theriogenology.2014.07.024

Mellado, M., Cantii, L., \& Suirez, J.E. (1996). Effects of body condition, length of breeding period, buck:doe ratio, and month of breeding on kidding rates in goats under extensive conditions in arid zones of Mexico. Small Ruminant Research, 23, 29-35. Doi: 10.1016/S0921-4488(96)00896-6

Mellado, M., Cárdenas, G., \& Ruíz, F. (2000). Mating behavior of bucks and does in goat operations under range conditions. Applied Animal Behavior Science, 67, 89-96. Doi: 10.1016/S0168-1591(99)00109-4

Memon, M.A., Bretzlaff, K.N., \& Ott, R.S. (1986). Comparison of semen collection techniques in goats. Theriogenology, 26, 823-827. Doi: 10.1016/0093-691X(86)90011-7

Menchaca, A., Miller, V., Salveraglio, V., \& Rubianes, E. (2007). Endocrine, luteal and follicular responses after the use of the short-term protocol to synchronize ovulation in goats. Animal Reproduction Science, 102, 76-87. Doi: 10.1016/j.anireprosci.2006.10.001

Nasar, A.M., Rahman, A., Abdullah, R.B., \& Wan-Khadijah, W.E. (2008). A review of reproductive biotechnologies and their application in goat. Biotechnology, 7, 371-384. Doi: 10.3923/ biotech.2008.371.384

Navanukraw, C., Khanthusaeng, V., Kraisoon, A., \& Uriyapongson, S. (2014). Estrous and ovulatory responses following cervical artificial insemination in Thai-native goats given a new or once-used controlled internal drug release with human chorionic gonadotropin. Tropical Animal Health and Production, 46, 1441-1446. Doi: 10.1007/s11250-014-0662-x

Ritar, A.J., Ball, P.D., \& O’May, P.J. (1990). Artificial insemination of Cashmere goats: effects on fertility and fecundity of intravaginal treatment, method and time of insemination, semen freezing process, number of motile spermatozoa and age of females. Reproduction Fertility and Development, 2, 377-384. Doi: $10.1071 /$ rd9900377

Salvador, I., Viudes-de-Castro, M.P., Bernacer, J., Gómez, E.A., \& Silvestre, M.A. (2005). Factors affecting pregnancy rate in artificial insemination with frozen semen during non-breeding season in Murciano- 
Granadina goats: a field assay. Reproduction in Domestic Animals, 40, 526-529. Doi: 10.1111/j.14390531.2005.00624.x

Sen, U. \& Onder, H. (2016). The effect of estrus synchronization programs on parturition time and some reproductive characteristics of Saanen goats. Journal of Applied Animal Research, 44, 376-379. Doi: $10.1080 / 09712119.2015 .1091348$

Véliz, F.G., Poindron, P., Malpaux, B., \& Delgadillo, J.A. (2006). Positive correlation between the body weight of anestrous goats and their response to the male effect with sexually active bucks. Reproduction, Nutrition, Development, 46, 657-661. Doi: 10.1051/rnd:2006039

Vilariño, M., Rubianes, E., \& Menchaca, A. (2011). Re-use of intravaginal progesterone devices associated with the short-term protocol for timed artificial insemination in goats. Theriogenology, 75, 1195-2000. Doi: 10.1016/j.theriogenology.2010.11.030

Zarazaga, L.A., Gatica, M.A., Gallego-Calvo, M.A., \& Guzmán, J.L. (2018). When using photostimulated bucks to induce the male effect in female goats living at Mediterranean latitudes, a male: female ratio of 1:20 is optimum. Journal of Applied Animal Research, 46, 883-887. Doi: 10.1080/097121 19.2017.1418669 